\title{
EL REPARTO DE COMPETENCIAS ENTRE ESTADO Y COMUNIDADES AUTÓNOMAS EN MATERIA DE EMPLEO A LA LUZ DE LA JURISPRUDENCIA DEL TRIBUNAL CONSTITUCIONAL: A PROPÓSITO DE LA COMPETENCIA DEL SERVICIO PÚBLICO DE EMPLEO ESTATAL PARA GESTIONAR LOS PROGRAMAS FINANCIADOS A CARGO DE LA RESERVA DE CRÉDITO ESTABLECIDA EN SU PRESUPUESTO DE GASTOS
}

\author{
Elisabet ERRANDONEA ULAZIA \\ Profesora Titular de Universidad de Derecho \\ del Trabajo y de la Seguridad Social \\ Facultad de Relaciones Laborales y Trabajo Social \\ Universidad del País Vasco-Euskal Herriko Unibertsitatea, UPV-EHU \\ elisabet.errandonea@ebu.eus
}

\section{INTRODUCCIÓN}

El empleo es, sin duda, una cuestión clave en nuestras sociedades. En el ordenamiento español, el Real Decreto Legislativo 3/2015, de 23 de octubre, por el que se aprueba el Texto Refundido de la Ley de Empleo, viene a sustituir a la Ley 56/2003, de 16 de diciembre, de Empleo, la cual integra de forma regularizada, aclarada y armonizada con otras disposiciones legales. Es este texto de octubre de 2015 el que define en su artículo primero lo que ha de entenderse por el término política de empleo. De acuerdo con este:

«Teniendo en cuenta lo establecido en los arts. 40 y 41 de la Constitución española, la política de empleo es el conjunto de decisiones adoptadas por el Estado y las Comunidades Autónomas que tienen por finalidad el desarrollo de programas y medidas tendentes a la consecución del pleno empleo, así como la calidad en el empleo, a la adecuación cuantitativa y 
cualitativa de la oferta y demanda de empleo, a la reducción y a la debida protección de las situaciones de desempleo.

La política de empleo se desarrollará, dentro de las orientaciones generales de la política económica, en el ámbito de la estrategia coordinada para el empleo regulada por el Tratado de Funcionamiento de la Unión Europea».

Al hacer una lectura de la jurisprudencia del Tribunal Constitucional en materia de empleo de los últimos años puede verse que hay un número no desdeñable de sentencias de dicho Tribunal sobre esta materia en las que se discute la distribución de competencias entre el Estado y las Comunidades Autónomas.

Distintas Comunidades Autónomas han impugnado reiteradamente normas de rango diverso relacionadas con la materia de empleo al entender que las mismas contenían preceptos que vulneraban sus competencias en dicha materia y contrariaban el orden constitucional.

En el mencionado repaso de la jurisprudencia constitucional en materia de empleo puede observarse cómo existe un precepto cuyo contenido ha sido discutido en repetidas ocasiones en los recursos de inconstitucionalidad presentados. Se trata del art. 13.e) de la Ley 56/2003, de 16 de diciembre, que posteriormente pasó al apartado $b$ ) del mismo artículo y actualmente se encuentra en el art. 18, apartado b), del Real Decreto Legislativo 3/2015, de 23 de octubre, por el que se aprueba el Texto Refundido de la Ley de Empleo.

Así, hemos considerado de interés reparar en el contenido de dichas sentencias para conocer cuál ha sido el sentido de los pronunciamientos del Tribunal Constitucional en relación con la atribución al Servicio Público de Empleo Estatal de competencias para gestionar los programas financiados con cargo a la reserva de crédito establecida en su presupuesto de gastos recogida en tal precepto.

$\mathrm{Al}$ tratarse de una competencia de gestión, se trataría, en principio, de un terreno que corresponde a las Comunidades Autónomas y que el legislador otorga a un órgano estatal. Veremos así cuáles han sido las respuestas dadas por el Tribunal Constitucional a los sucesivos conflictos planteados en relación con dicho artículo.

Comenzaremos exponiendo cuáles son los diversos títulos competenciales que recoge la Constitución española aplicables en materia de empleo. Nos referiremos a continuación a la evolución que ha experimentado el precepto que regula dicha atribución de competencias a favor del 
Servicio Público de Empleo Estatal. Después haremos un repaso de las sentencias del Tribunal Constitucional en las que se ha discutido la mencionada atribución de competencias. Terminaremos, en último lugar, con una pequeña conclusión.

\section{EL REPARTO DE COMPETENCIAS ENTRE ESTADO Y COMUNIDADES AUTÓNOMAS EN MATERIA DE EMPLEO: LOS DIVERSOS TÍTULOS COMPENTENCIALES POSIBLES EN MATERIA DE EMPLEO}

Este reparto de competencias entre el Estado y las Comunidades Autónomas en materia de empleo no ha resultado siempre sencillo y en reiteradas ocasiones las Comunidades Autónomas han entendido que la Administración del Estado se estaba atribuyendo competencias que correspondían a dichas administraciones autonómicas. Así, este reparto de competencias ha dado lugar a sucesivos recursos de inconstitucionalidad que ha tenido que resolver el Tribunal Constitucional en base a preceptos diversos del texto constitucional.

Son varios preceptos constitucionales los que se han venido utilizando como títulos competenciales en materia de empleo y así se recoge en las diversas normas dictadas en esta materia, que es común que se apoyen en más de un título competencial de la Constitución.

Por su parte, el Tribunal Constitucional no siempre ha recurrido a los mismos preceptos constitucionales a la hora de situar la materia de empleo en los títulos competenciales apropiados en cada caso. En algunos de los recursos de inconstitucionalidad planteados es precisamente esta cuestión del título competencial aplicable una de las cuestiones objeto de controversia $^{1}$. A esto hay que añadir que dicha cuestión tampoco se ha resuel-

${ }^{1}$ Es el caso de la STC 144/2012, de 18 de diciembre, que resuelve un recurso de inconstitucionalidad planteado por la Generalitat de Cataluña en relación con el Real Decreto 1046/2003, de 1 de agosto, que regulaba el subsistema de formación profesional continua. Esta norma decía dictarse al amparo de lo previsto en el art. 149.1.7. ${ }^{a}, 13$. $^{a}$ y 17 . $^{a}$ de la Constitución; fundamentación esta que, entre otras cuestiones, es discutida por la Generalitat de Cataluña. En su pronunciamiento, el Tribunal Constitucional considera que debe rechazarse la inserción de la materia regulada en dicho real decreto dentro del ámbito del art. 149.1.17. å CE («legislación básica y régimen económico de la Seguridad Social, sin perjuicio de la ejecución de sus servicios por las Comunidades Autónomas»), puesto que entiende que la formación profesional no forma parte del sistema de Seguridad Social ni las cuotas abonadas en tal concepto son recursos de la Seguridad Social integrados en su caja única. También en la STC 88/2014, de 9 de junio, que resuelve el conflicto planteado por la Xunta de Galicia 
to siempre de forma unánime dentro del mismo Tribunal Constitucional, ya que dicha atribución del título competencial aplicable ha sido tratada en más de un voto particular formulado a dichas sentencias ${ }^{2}$. Es por ello que dedicaremos este apartado a exponer cuáles son estos preceptos constitucionales.

Son diversas las disposiciones constitucionales recogidas por los arts. 148 y 149 CE que han de mencionarse en este apartado, dada su conexión con la materia de empleo que estamos tratando, aunque ninguna de ellas hace referencia explícita a dicho término.

Hemos de referirnos, en primer lugar, al reparto de competencias en materia laboral y de seguridad social. Ello nos remite a los apartados 7. ${ }^{a}$ y 17. a del art. 149.1 CE. El primero de ellos atribuye al Estado competencia exclusiva en materia de «legislación laboral, sin perjuicio de su ejecución por los órganos de las Comunidades Autónomas» (art. 149.1.7. ${ }^{a} \mathrm{CE}$ ). El segundo de ellos atribuye competencia exclusiva al Estado en cuanto a la «legislación básica y el régimen económico de la Seguridad Social, sin perjuicio de la ejecución de sus servicios por las Comunidades Autónomas» (art. 149.1.17. ${ }^{a} \mathrm{CE}$ ).

Además, la clara conexión que presentan la política de empleo y la política económica nos remite a los preceptos dedicados a dicha política económica ${ }^{3}$. Así, el art. 131 CE establece: «1. El Estado, mediante ley, podrá planificar la actividad económica general para atender a las necesidades colectivas, equilibrar y armonizar el desarrollo regional y sectorial, y estimular el crecimiento de la renta y de la riqueza y su más justa distribución. 2. El Gobierno elaborará los proyectos de planificación de acuerdo con las previsiones que le sean suministradas por las Comunidades Autónomas y el asesoramiento y colaboración de los sindicatos y otras organizaciones profesionales, empresariales y económicas».

con relación al Real Decreto 395/2007, de 23 de marzo, por el que se regula el subsistema de formación profesional para el empleo, se cuestiona la aplicación del mismo art. 149.1.17. ${ }^{\circledR}$ $\mathrm{CE}$, que es rechazada por el Tribunal.

2 Ello ha sucedido en la STC 144/2012, de 18 de diciembre, ya citada, en la que una magistrada expresa a través de un voto particular su disconformidad, entre otras cuestiones, con uno de los títulos competenciales dado por bueno en dicha sentencia. La discrepancia en cuanto al título competencial considerado aplicable por el Tribunal Constitucional se manifiesta también en votos particulares formulados en la STC 100/2017 sobre el Plan Prepara y las SSTC 153 y 156/2017 sobre el Plan de Activación para el Empleo.

3 J. L. Monereo Pérez et al., Manual de política y derecho del empleo (instituciones, relaciones de empleo, marco legal de las políticas públicas y derecho social del empleo), Madrid, Tecnos, 2011, p. 74. 
Del mismo modo, ha de hacerse referencia al art. 149.1.13. ${ }^{a} \mathrm{CE}$, que atribuye al Estado competencia exclusiva sobre «bases y coordinación de la planificación general de la actividad económica», así como al 148.1.13. a , según el cual las Comunidades Autónomas podrán asumir competencias en materia de «fomento del desarrollo económico de la Comunidad Autónoma dentro de los objetivos marcados por la política económica nacional». Como ha señalado la doctrina, la interdependencia de la materia de empleo y la política económica permite a las Comunidades Autónomas asumir competencias respecto del fomento de su desarrollo productivo, eso sí, dentro de las metas fijadas por la política económica del Estado. Así, para que estas políticas sean eficientes se requiere un tratamiento más descentralizado y diferenciado que tenga en cuenta las peculiares características y disfunciones de los diversos mercados en presencia ${ }^{4}$.

\section{La competencia exclusiva del Estado sobre «legislación laboral» sin perjuicio de su ejecución por los órganos de las Comunidades Autónomas del art. 149.1.7. ${ }^{\text {C }} \mathrm{CE}$}

Este precepto atribuye, por un lado, competencias a la Administración del Estado y, por otro, competencias a los órganos de las Comunidades Autónomas, sobre las que trataremos a continuación.

\section{A. La competencia exclusiva del Estado sobre «legislación laboral»}

Como se ha señalado ya, el art. 149.1.7. ${ }^{a}$ CE atribuye al Estado la competencia exclusiva sobre «legislación laboral», término este cuyo significado necesita una mayor precisión. La interpretación de lo que debe entenderse por «legislación laboral» no ha sido siempre pacífica para la doctrina, aunque sí se puede hablar de una línea doctrinal elaborada por el Tribunal Constitucional que interpreta este concepto de un modo más o menos uniforme 5 .

${ }^{4}$ Ibid., pp. 74 y 75.

5 M. Rodríguez-Piñero Royo y M. ${ }^{a}$ L. Pérez Guerrero, «El reparto competencial entre el Estado y la Comunidad Autónoma andaluza en materia de empleo: perspectivas tras el nuevo Estatuto de Autonomía», Temas laborales: Revista andaluza de trabajo y bienestar social, núm. 100 (2009), p. 197. 
En cuanto a si dicho término de «legislación laboral» ha de entenderse en un sentido formal o material, el Tribunal Constitucional ha interpretado que su sentido es el material y, por tanto, abarca no solo la potestad legislativa, sino también la reglamentaria que incluye a los reglamentos ejecutivos $^{6}$. Ello deja a salvo la competencia de las Comunidades Autónomas para dictar reglamentos internos de organización de los servicios correspondientes en materias de su competencia ${ }^{7}$.

También el Tribunal Constitucional ha llevado a cabo su interpretación respecto de cómo ha de ser entendido el término «laboral». Según esta, dicho término debe tener un sentido concreto y restringido, referido solo al trabajo por cuenta ajena ${ }^{8}$. De tal forma que esta calificación de «laboral» recogida por la Constitución queda referida a cualquiera de las instituciones que regula el trabajo por cuenta ajena que incidan directamente sobre la prestación laboral y su remuneración, o bien actúen con una función de regulación o administración sobre la relación de trabajo de forma que incidan sobre su contenido?

Aunque con posterioridad, la STC 195/1996 parece que amplía la mencionada interpretación, puesto que considera que las materias de colocación, empleo, ayudas de fomento del empleo y formación profesional ocu-

${ }^{6}$ La STC 18/1982, de 4 de mayo, afirma en su fundamento jurídico 5: «Cuando la Constitución emplea el término "legislación laboral" y lo atribuye a la competencia estatal incluye también en el término los reglamentos tradicionalmente llamados ejecutivos, es decir, aquellos que aparecen como desarrollo de la ley y, por ende, como complementarios de la misma, pues si ello no fuera así se frustraría la finalidad del precepto constitucional de mantener una uniformidad en la ordenación jurídica de la materia, que solo mediante una colaboración entre ley y reglamento (o mediante una hipertrofia inconveniente desde el punto de vista de política legislativa) del instrumento legal puede lograrse».

En el mismo sentido las Sentencias del Tribunal Constitucional 57/1982, de 27 de julio, FJ 11, y 95/2002, de 25 de abril, FJ8, entre otras.

7 M. Rodríguez-Piñero Royo y M. ${ }^{a}$ L. PÉrez Guerrero, «El reparto competencial entre el Estado...», op. cit., p. 199. Así también las SSTC 57/1982, FJ11, y 7/1985, FJ4.

8 STC 35/1982, FJ 2: «El concepto de "legislación laboral", cuyo primer término tiene la considerable fuerza expansiva que ya hemos señalado, no puede ser entendido también como potencialmente ilimitado en función del segundo, cosa que inevitablemente sucedería si el adjetivo "laboral" se entendiera como indicativo de cualquier referencia al mundo del trabajo. Es por ello forzoso dar a ese adjetivo un sentido concreto y restringido, coincidente por lo demás con el uso habitual, como referido solo al trabajo por cuenta ajena, entendiendo, por consiguiente, como legislación laboral aquella que regula directamente la relación laboral, es decir, para recoger los términos de la Ley 8/1980, de 10 de marzo, la relación que media entre los trabajadores que presten servicios retribuidos por cuenta ajena y los empresarios en favor de los que y bajo la dirección de quienes se prestan estos servicios, con las exclusiones y excepciones que en dicha ley (art. 1.3) se indican».

${ }^{9}$ M. Rodríguez-Piñero Royo y M. ${ }^{a}$ L. Pérez Guerrero, «El reparto competencial entre el Estado...», op. cit., pp. 200-201. 
pacional se incluyen en la materia de «legislación laboral» ${ }^{10}$. De acuerdo con dicha sentencia ha de entenderse que las acciones de estímulo a la contratación laboral en sus diversas modalidades se insertan sin dificultad dentro del título competencial del art. 149.1.7. ${ }^{a} \mathrm{CE}$.

Esta inclusión de dichas materias por parte del Tribunal Constitucional dentro del art. 149.1.7. ${ }^{a}$ por tratarse de acciones de estímulo a la contratación laboral en sus diversas modalidades ha sido calificada como simplista, puesto que la realidad pone en evidencia el carácter transversal de la política de empleo ${ }^{11}$.

En sentencias posteriores, sin embargo, el Tribunal Constitucional reconoce que la materia de empleo puede vincularse tanto al título competencial del art. 149.1.7. ${ }^{a} \mathrm{CE}$ (legislación laboral) como al del 149.1.13. ${ }^{a} \mathrm{CE}$ (bases y coordinación de la planificación general de la actividad económica), al que nos referiremos posteriormente.

\section{B. La competencia de los órganos de las Comunidades Autónomas de ejecución de la legislación laboral}

Tras la atribución al Estado de la competencia exclusiva en materia de legislación laboral, el precepto constitucional del art. 149.1.7. ${ }^{a}$ añade que tal atribución se hace «sin perjuicio de su ejecución por los órganos de las Comunidades Autónomas».

Así, de acuerdo con sus Estatutos de Autonomía, todas las Comunidades Autónomas tienen en la actualidad competencias para ejecutar la legislación laboral del Estado. De acuerdo con el Tribunal Constitucional, hay que «convenir en que la actividad de ejecución vinculada al ámbito laboral comprende el desarrollo del conjunto de actuaciones preciso para la puesta en práctica de la normativa reguladora del conjunto del sistema de relaciones laborales» (STC 194/1994, FJ 3) ${ }^{12}$.

Esta actividad de ejecución incluye: vigilar la correcta observancia de la ley (es decir, lo referido a las actuaciones de inspección del cumplimiento de normas laborales y las correspondientes sanciones), las autorizaciones

${ }^{10}$ F. Cavas Martínez y C. SÁnchez Trigueros, «La distribución de competencias entre el Estado y las Comunidades Autónomas en materia de trabajo, empleo y protección social: una sinopsis», Anales del Derecho. Universidad de Murcia, núm. 23 (2005), p. 107.

${ }^{11}$ J. L. Monereo Pérez et al., Manual de política y Derecho del empleo..., op. cit., p. 74.

12 Esta sentencia del Tribunal Constitucional da la razón al Gobierno vasco en un conflicto planteado en materia de celebración de elecciones a los órganos de representación de los trabajadores en la empresa. 
que la normativa exige para llevar a cabo determinadas actividades (como, por ejemplo, para la actuación de las Empresas de Trabajo Temporal), así como la organización de los servicios administrativos precisos para llevar a cabo dichas funciones ${ }^{13}$. Ha de entenderse incluida también la competencia de «emanación de reglamentos internos de organización de los servicios necesarios para ello y de regulación de la propia competencia funcional de ejecución y, en general, el desarrollo del conjunto de actuaciones preciso para la puesta en práctica de la normativa reguladora del conjunto del sistema de relaciones laborales» (STC 51/2006, FJ 4).

\section{La competencia exclusiva del Estado en materia de «legislación básica» y «régimen económico de la Seguridad Social»}

El art. 149.1.17. a atribuye al Estado, en primer lugar, la competencia exclusiva sobre la «legislación básica» de Seguridad Social, a diferencia del precepto anterior que se refería a la legislación laboral sin más calificativos. De acuerdo con la doctrina, la interpretación que ha de hacerse del término «bases» al que se refiere el art. 149.1 CE incluye los criterios generales de regulación de un sector del ordenamiento jurídico o de una materia jurídica que deben ser comunes para todo el Estado ${ }^{14}$.

En cuanto a la atribución al Estado de la competencia exclusiva en materia de régimen económico de la Seguridad Social, el Tribunal Constitucional interpreta que esta no se reduce a la potestad normativa, sino que implica también la capacidad de gestión de los recursos económicos y la administración financiera del sistema ${ }^{15}$.

${ }^{13}$ M. Rodríguez-Piñero Royo y M. ${ }^{a}$ L. Pérez Guerrero, «El reparto competencial entre el Estado...», op. cit., pp. 212-213.

${ }^{14}$ Ibid., p. 202.

15 «Del art. 149.1.17. a de la Constitución no puede extraerse la apresurada conclusión de que en materia de régimen económico de Seguridad Social el Estado retenga solo potestades normativas. Que ello no es así se deduce sin dificultad de un análisis sistemático, histórico y teleológico del precepto constitucional. El designio perseguido con el acantonamiento del "régimen económico" dentro de la competencia exclusiva del Estado no ha sido otro, con toda claridad, que el de preservar la unidad del sistema español de Seguridad Social y el mantenimiento de "un régimen público", es decir, único y unitario de Seguridad Social para todos los ciudadanos (art. 41 de la Constitución), que garantice al tiempo la igualdad de todos los españoles en el ejercicio de los derechos y deberes en materia de Seguridad Social (art. 149.1.1. ${ }^{a}$ de la Constitución). Debe tenerse en cuenta a este propósito que en el momento de aprobarse la Constitución había sido ya creada la Tesorería General de la Seguridad Social para hacer efectivos los principios de solidaridad financiera y de unidad de caja, y este dato resulta relevante para la correcta interpretación del art. 149.1.17. ${ }^{\mathrm{a}}$, en la medi- 
En base a dicha delimitación de competencias en materia de Seguridad Social queda de forma exclusiva en manos del Estado la adopción de medidas de fomento del empleo, como el establecimiento de bonificaciones en materia de cuotas de Seguridad Social, la jubilación anticipada o la regulación de las prestaciones por desempleo, incluyendo su modalidad de pago único ${ }^{16}$.

Este título competencial del art. 149.1.17. ${ }^{a}$ CE ha sido, sin embargo, descartado por el Tribunal Constitucional en materias como son la regulación del subsistema de formación profesional para el empleo (STC 88/2014, FJ 3) o en relación con programas para el empleo, como el programa PREPARA (STC 100/2017, FJ 5) y el Plan de Activación para el Empleo (STC 153/2017, FJ 3).

\section{Las competencias de las Comunidades Autónomas en materia de fomento del desarrollo económico del 148.1.13. ${ }^{a} \mathrm{CE}$}

En base a este precepto del art. 148.1.13. ${ }^{a} \mathrm{CE}$, las Comunidades Autónomas pueden asumir competencias en materia de «fomento del desarrollo económico de la Comunidad Autónoma dentro de los objetivos enmarcados por la política económica nacional»; precepto este en el que la mayoría de la doctrina ha hecho residir la materia de empleo ${ }^{17}$. Así ha sucedido en materias relacionadas con ciertos aspectos de las políticas de fomento del empleo, como es el caso de las subvenciones a la contratación de trabajadores pertenecientes a colectivos específicos dentro del territorio de cada Comunidad Autónoma ${ }^{18}$. Así, todos los Estatutos de Autonomía han asumido estas competencias como exclusivas utilizando denominaciones

\footnotetext{
da en que, como cabe deducir de los antecedentes y de los debates parlamentarios que culminaron en la aprobación del texto del citado precepto constitucional, la mención separada del "régimen económico" como función exclusiva del Estado trataba de garantizar la unidad del sistema de la Seguridad Social, y no solo la unidad de su regulación jurídica, impidiendo diversas políticas territoriales de Seguridad Social en cada una de las Comunidades Autónomas [...]. Por ello es competencia exclusiva del Estado, ejercida a través de la Tesorería General de la Seguridad Social, "la gestión de los recursos económicos y la administración financiera del sistema, en aplicación de los principios de solidaridad financiera y caja única"» (STC 124/1989, FJ 3).

16 J. L. Monereo Pérez et al., Manual de política y Derecho del empleo..., op. cit., p. 75.

17 M. Rodríguez-Piñero Royo y M. ${ }^{a}$ L. Pérez Guerrero, «El reparto competencial entre el Estado...», op. cit., p. 217.

${ }^{18}$ F. Cavas Martínez y C. Sánchez Trigueros, «La distribución de competencias...», op. cit., pp. 106-107.
} 
semejantes (como son la planificación, ordenación, promoción o fomento de la actividad y el desarrollo económico de la Comunidad Autónoma), lo cual permite a los órganos de gobierno de las Comunidades Autónomas desarrollar acciones de política de fomento de la ocupación ${ }^{19}$.

Como ha señalado la doctrina, la interdependencia de la materia de empleo y la política económica permite a las Comunidades Autónomas asumir competencias respecto del fomento de su desarrollo productivo, eso sí, dentro de las metas fijadas por la política económica del Estado; así, para que estas políticas sean eficientes se requiere un tratamiento más descentralizado y diferenciado que tenga en cuenta las peculiares características y disfunciones de los diversos mercados en presencia ${ }^{20}$.

\section{La competencia exclusiva del Estado en materia de bases y coordinación de la planificación general de la actividad económica según el 149.1.13. ${ }^{a} \mathrm{CE}$}

También este precepto constituye un título competencial en materia de empleo de acuerdo con la interpretación que lleva a cabo el Tribunal Constitucional en varias de sus sentencias.

El art. 149.1.13. ${ }^{a}$ CE otorga al Estado la competencia exclusiva en materia de bases y coordinación de la planificación general de la actividad económica. «Cuando la Constitución utiliza el término bases (así en el art. 149.1.11. ${ }^{a}, 13 .^{a}$ y 18. ${ }^{a}$ ) está comprendiendo funciones normativas que aseguren, en lo que es menester un común uniforme, unas reglas a partir de las cuales las Comunidades Autónomas que tengan asumidas competencias en la materia puedan ejercerlas, pero estas competencias no se agotan con las propias legislativas, pues cuando la preservación de un tratamiento uniforme reclame el complemento reglamentario, y aun el ejecutivo, se justifica la reserva de estas competencias en la medida indispensable» (SSTC 57/1983, de 28 de junio, FJ 7, y 182/2013, de 23 de octubre, FJ 4).

De acuerdo con la doctrina del Tribunal Constitucional, este art. 149.1.13. ${ }^{a} \mathrm{CE}$ ampara «tanto las normas estatales que fijen las líneas directrices y los criterios globales de ordenación de un sector concreto como las previsiones de acciones o medidas singulares que sean necesarias

19 M. C. Palomeque López y M. Álvarez de la Rosa, Derecho del trabajo, 25. a ed., Madrid, Editorial Universitaria Ramón Areces, 2017, p. 172.

20 J. L. Monereo Pérez et al., Manual de politica y Derecho del empleo..., op. cit., pp. 74 y 75 . 
para alcanzar los fines propuestos dentro de la ordenación de cada sector. Sin embargo, dicha competencia estatal no puede extenderse hasta incluir cualquier acción de naturaleza económica si no posee una incidencia directa y significativa sobre la actividad económica general, pues, en otro caso, se vaciaría de contenido una materia y un título competencial más específico» (STC 77/2004, FJ 4).

Además, el Tribunal Constitucional ha interpretado en algunos casos que procede aplicar el título competencial del art. 149.1.13. ${ }^{a} \mathrm{CE}$ y no el del art. 149.1.7. ${ }^{a} \mathrm{CE}$. Así entiende que: «La movilización de recursos financieros destinados a regular el mercado laboral y el pleno empleo concierne a ámbitos que no se limitan a lo que se viene entendiendo como régimen o materia laboral, aunque guarden conexión con esta, sino que se trata "de medidas que inciden en el mercado de trabajo globalmente considerado, dando cumplimiento a la directriz contenida en el art. 40.1 in fine CE, y que tienen tras de sí el respaldo competencial del art. 149.1.13. ${ }^{a} \mathrm{CE}$, que atribuye al Estado la competencia exclusiva sobre bases y coordinación de la planificación general de la actividad económica" (STC 95/2001, de 25 de abril, FJ 11). En consecuencia [...] el Estado ostenta, al amparo de su competencia sobre las bases y coordinación de la planificación general de la actividad económica (art. 149.1.13. ${ }^{a} \mathrm{CE}$ ), la facultad de adoptar medidas en materia de fomento del empleo que, en tanto no incidan en la regulación de la relación laboral, constituyen una materia distinta de la propiamente laboral a la que se refiere el art. 149.1.7. ${ }^{a}$ CE» (SSTC 22/2014, FJ 4, y 179/2016, FJ 2).

Del mismo art. 149.1.13. ${ }^{a} \mathrm{CE}$ debe deducirse también que corresponde a las Comunidades Autónomas, en cualquier caso, el desarrollo en cada ámbito territorial de la mencionada competencia estatal sobre las «bases y coordinación de la planificación general de la actividad económica» ${ }^{21}$. Así, según el Tribunal Constitucional es a las Comunidades Autónomas a quienes corresponde ejecutar las normas dictadas en base a la competencia estatal sobre bases y coordinación de la planificación general de la actividad económica, sin que en el ejercicio de su competencia normativa el Estado pueda desapoderar a las mismas de las competencias que hayan asumido en sus Estatutos de Autonomía (STC 22/2014, FJ 7).

${ }^{21}$ M. C. Palomeque López y M. Álvarez de la Rosa, Derecho del trabajo, op. cit., p. 171. 


\section{LA COMPENTENCIA DEL SERVICIO PÚBLICO DE EMPLEO ESTATAL PARA GESTIONAR LOS PROGRAMAS FINANCIADOS A CARGO DE LA RESERVA DE CRÉDITO ESTABLECIDA EN SU PRESUPUESTO DE GASTOS}

Esta competencia para gestionar acciones y medidas financiadas con cargo a la reserva de crédito del Servicio Público de Empleo Estatal fue incluida en la Ley 56/2003, de 16 de diciembre, de Empleo, en su art. 13.e). Esta norma establecía un listado cerrado de programas con tres apartados, que podían ser gestionados por el Instituto Nacional de Empleo (en adelante, INEM) con cargo a dicha reserva de crédito. Esta norma fue posteriormente modificada por el Real Decreto-ley 3/2011, que la situaba en el apartado $b$ ) y ampliaba las posibilidades de gestión a través de la misma ${ }^{22}$, y en la actualidad se halla en el art. 18, apartado $b$ ), del Real Decreto Legislativo 3/2015, de 23 de octubre, por el que se aprueba el Texto Refundido de la Ley de Empleo ${ }^{23}$.

22 C. SerRano FalCón, «Concepto y régimen jurídico, composición organizativa y competencias del Servicio Público de Empleo Estatal», en F. VALDÉs-DAL-RÉ y G. M. ${ }^{a}$ SobrinO GonzÁlez (dirs.), Comentarios a la Ley de Empleo, Madrid, La Ley, 2012, p. 145.

23 De acuerdo con la misma, es competencia del Servicio Público de Empleo Estatal: «b) Gestionar los servicios y programas financiados con cargo a la reserva de crédito establecida en su presupuesto de gastos. Estos servicios y programas serán: 1) servicios y programas cuya ejecución afecte a un ámbito geográfico superior al de una Comunidad Autónoma, cuando estos exijan la movilidad geográfica de las personas desempleadas o trabajadoras participantes en los mismos a otra Comunidad Autónoma distinta a la suya o a otro país y precisen de una coordinación unificada; 2) programas cuya ejecución afecte a un ámbito geográfico superior al de una Comunidad Autónoma sin que implique la movilidad geográfica de los desempleados o trabajadores participantes en los mismos, cuando precisen una coordinación unificada y previo acuerdo entre el Servicio Público de Empleo Estatal y las Comunidades Autónomas en las que vayan a ejecutarse los citados programas; 3 ) servicios y programas dirigidos tanto a las personas demandantes de empleo como a las personas ocupadas para la mejora de su ocupación mediante la colaboración del Servicio Público de Empleo Estatal con órganos de la Administración General del Estado o sus organismos autónomos, para la realización de acciones formativas, entre otras, aquellas que tengan como objetivo la generación de empleo de calidad y la mejora de oportunidades de las personas trabajadoras, en particular cuando se desarrollen en el marco de planes, estrategias o programas de ámbito estatal, y ejecución de obras y servicios de interés general y social relativos a competencias exclusivas del Estado; 4) servicios y programas de intermediación y políticas activas de empleo cuyo objetivo sea la integración laboral de trabajadores inmigrantes realizados en sus países de origen, facilitando la ordenación de los flujos migratorios; 5) programas que se establezcan con carácter excepcional y duración determinada cuya ejecución afecte a todo el territorio nacional, siendo imprescindible su gestión centralizada a los efectos de garantizar la efectividad de las mismas, así como idénticas posibilidades de obtención y disfrute a todos los potenciales bene- 
La Ley Básica de Empleo (Ley 51/1980, de 8 de octubre) no incluía esta función de gestionar los programas financiados a cargo de la reserva de crédito entre las competencias atribuidas al INEM, lo cual se explica porque en aquel momento la gestión completa de las políticas de empleo quedaba en manos del INEM, ya que todavía no existían los Servicios Públicos de Empleo Autonómicos ni estaban traspasadas las correspondientes competencias en materia de políticas activas de empleo ${ }^{24}$.

Aunque no es por primera vez en la citada Ley 56/2003 donde se incluye dicha competencia para el INEM, sino que fue dos años antes cuando se incluyó por primera vez en la Ley 13/2000, de 28 de diciembre, de Presupuestos Generales del Estado para 2001. En esta norma se habilitaba legal y presupuestariamente al INEM para gestionar de forma directa varias líneas de programas experimentales destinados a explorar alternativas de inserción con la finalidad de extenderlas a todo el territorio del Estado una vez evaluada su eficacia ${ }^{25}$.

Sin embargo, en la Ley 52/2002, de 30 de diciembre, de Presupuestos Generales del Estado para 2003, la gestión de dichos programas no se atribuye al INEM, con el objetivo de que la misma fuera traspasada a las Comunidades Autónomas con competencias en la materia ${ }^{26}$. Pero al año siguiente, nuevamente se vuelven a regular los programas experimentales de empleo gestionados por el INEM por la Orden TAS/2643/2003, de 18 de septiembre, por la que se regulan las bases para la concesión de subvenciones para la puesta en práctica de programas experimentales en materia de empleo ${ }^{27}$.

Las competencias asignadas al Servicio Público de Empleo Estatal (en adelante, SEPE) por la Ley de Empleo 56/2003 fueron modificadas por el Real Decreto-ley 3/2011. De entre las modificaciones producidas destacan las siguientes: se sustituye el término programas por el de acciones y medidas, se amplían las acciones y medidas para la realización de acciones formativas, y se añade un nuevo apartado que amplía las competencias del SEPE en esta materia ${ }^{28}$.

ficiarios. La reserva de crédito a que hace referencia este párrafo se dotará anualmente, previo informe de la Conferencia Sectorial de Empleo y Asuntos Laborales, por la Ley de Presupuestos Generales del Estado. De los resultados de las actuaciones financiadas con cargo a los mismos se informará anualmente a dicha Conferencia Sectorial».

${ }^{24}$ Ibid., p. 144.

${ }^{25}$ Ibid., p. 144.

${ }^{26}$ Ibid., p. 144.

${ }^{27}$ Ibid., p. 145.

${ }^{28}$ C. Serrano Falcón, «El servicio público de empleo estatal», en J. L. Monereo Pérez, J. A. Fernández Bernat y B. M. López Insúa (dirs. y coords.), Las Políticas Activas de 
Elisabet Errandonea Ulazia El reparto de competencias entre Estado y Comunidades...

Como hemos dicho ya, esta atribución al SEPE de competencias para gestionar la reserva de crédito establecida en su presupuesto de gastos se mantiene vigente en el art. 18.h) del actual texto de la Ley de Empleo.

\section{EL REPARTO DE COMPETENCIAS ENTRE EL ESTADO Y LAS COMUNIDADES AUTÓNOMAS A PROPÓSITO DE LA ATRIBUCIÓN AL SERVICIO PÚBLICO DE EMPLEO ESTATAL DE COMPETENCIAS PARA GESTIONAR LOS PROGRAMAS FINANCIADOS CON CARGO A LA RESERVA DE CRÉDITO ESTABLECIDO EN SU PRESUPUESTO DE GASTOS EN LA JURISPRUDENCIA DEL TRIBUNAL CONSTITUCIONAL}

Abordaremos en este punto la atribución al SEPE de la gestión de los programas financiados con cargo a la reserva de crédito establecida en su presupuesto de gastos a la luz de la jurisprudencia del Tribunal Constitucional, al tratarse de una cuestión que ha sido recurrida ante los tribunales por entenderla como vulneradora de las competencias atribuidas a las Comunidades Autónomas.

\section{La atribución al Servicio Público de Empleo Estatal} de competencias para gestionar los programas financiados con cargo a la reserva de crédito establecida en su presupuesto de gastos en la Sentencia 22/2014, de 13 de febrero, en cuanto a la constitucionalidad de diversos preceptos de la Ley 56/2003, de 16 de diciembre, de Empleo

La Sentencia 22/2014, de 13 de febrero, resuelve un recurso de inconstitucionalidad presentado por el Parlamento de Cataluña contra algunos preceptos de la Ley 56/2003, de 16 de diciembre, de Empleo, al entender que algunos de sus preceptos vulneran el orden constitucional en cuanto a la atribución de competencias que realizan (entre ellos, la atribución de

Empleo: configuración y estudio de su regulación jurídica e institucional, Pamplona, Thomson Reuters-Aranzadi, 2016, pp. 369-370. 
competencias de gestión al SEPE para gestionar los programas con cargo a la reserva de crédito establecida en su presupuesto de gastos).

No puede dejar de señalarse que esta sentencia tarda diez años en ver la luz desde la interposición de dicho recurso registrado con fecha de 18 de marzo de 2004 hasta el 13 de febrero de 2014, lo cual resulta ciertamente llamativo.

El primer precepto impugnado al que nos vamos a referir es el entonces art. 13, letra e), apartados 1 y 2. Este artículo atribuía al SEPE competencias para «gestionar los programas financiados con cargo a la reserva de crédito establecida en su presupuesto de gastos. Estos programas serán: 1) programas cuya ejecución afecte a un ámbito geográfico superior al de una Comunidad Autónoma, cuando estos exijan la movilidad geográfica de los desempleados o trabajadores participantes en los mismos a otra Comunidad Autónoma distinta a la suya y precisen de una coordinación unificada; 2) programas para la mejora de la ocupación de los demandantes de empleo mediante la colaboración del Servicio Público de Empleo Estatal con órganos de la Administración General del Estado o sus organismos autónomos para la realización de acciones formativas y ejecución de obras y servicios de interés general y social relativas a competencias exclusivas del Estado».

El Parlamento de Cataluña impugnó esta norma por entender que invadía las competencias autonómicas de ejecución, ya que reservaban a un órgano del Estado la gestión centralizada de algunos programas para desempleados o trabajadores. De acuerdo con el mismo, la gestión centralizada de tales programas desconocía las competencias ejecutivas de la Generalitat contempladas en su Estatuto de Autonomía que atribuyen a Cataluña la competencia compartida sobre la ordenación de la actividad económica en Cataluña, así como la competencia de desarrollo y gestión de la planificación general de la actividad económica.

Ante estas alegaciones, el Tribunal Constitucional comienza por recordar que el Estado no puede ignorar que la competencia tanto para la ejecución de la legislación laboral (art. 149.1.7. ${ }^{a} \mathrm{CE}$ ) como para la ejecución de las normas dictadas, dada la competencia estatal sobre las bases y coordinación de la planificación general de la actividad económica (art. 149.1.13. . $\mathrm{CE}$ ), corresponden, en principio, a las Comunidades Autónomas, sin que el Estado, en el ejercicio de su competencia normativa, pueda desapoderarles de las competencias que han asumido en sus Estatutos de Autonomía (FJ 7).

Puesto que se plantean cuestiones relacionadas con la territorialidad de las competencias ejecutivas autonómicas y la utilización de la suprate- 
rritorialidad como criterio para atribuir competencias ejecutivas al Estado, el Tribunal Constitucional recuerda su doctrina al respecto, según la cual: «El principio de territorialidad de las competencias autonómicas significa [...] que esas competencias deben tener por objeto fenómenos, situaciones o relaciones radicadas en el territorio de la propia Comunidad Autónoma. Ello no implica necesariamente que cuando el fenómeno objeto de las competencias autonómicas se extiende a más de una Comunidad Autónoma, estas pierdan en todo caso y de forma automática la competencia, y que la titularidad de la misma deba trasladarse necesariamente al Estado; semejante traslado de la titularidad, que ha de ser excepcional, solo puede producirse cuando "no quepa establecer ningún punto de conexión que permita el ejercicio de las competencias autonómicas o cuando, además del carácter supraautonómico del fenómeno objeto de la competencia, no sea posible el fraccionamiento de la actividad pública ejercida sobre él y, aun en este caso, siempre que dicha actuación tampoco pueda ejercerse mediante mecanismos de cooperación o de coordinación y, por ello, requiera un grado de homogeneidad que solo pueda garantizar su atribución a un solo titular, forzosamente el Estado, y cuando sea necesario recurrir a un ente supraordenado con capacidad de integrar intereses contrapuestos de sus componentes parciales, sin olvidar el peligro inminente de daños irreparables"» (STC 244/2012, de 18 de diciembre, FJ 7).

En cuanto al apartado 1 de la letra $e$ ) del art. 13 impugnado, el Tribunal considera que, aunque no existe impedimento para desplazar las competencias autonómicas y que estas sean asumidas por el Estado en supuestos de supraterritorialidad, esta posibilidad tiene un carácter excepcional, ya que la regla general en el caso de competencias ejecutivas es que sean asumidas por las Comunidades Autónomas cuando ostenten competencias de dicha naturaleza. Y añade que esta excepcionalidad debe ser valorada en cada caso concreto y atendiendo a los argumentos que se aporten para justificar esa excepcionalidad y a que se establezca un criterio de delimitación competencial congruente con el régimen jurídico de la materia de que se trate, «lo que en este caso obliga a acudir a las disposiciones que reglamenten y desarrollen en el futuro los concretos programas» (FJ 7).

De esta manera rechaza que el precepto legal impugnado invada competencias autonómicas. A su entender, la reserva de la función ejecutiva al Estado no se prevé con carácter general, sino de modo puntual, solo cuando se demuestre la necesidad de coordinación unificada, y esta necesidad solo se podrá apreciar si concurre o no a la luz de las disposiciones que regulen los programas concretos. Con esta limitada argumentación, el Tribunal 
Constitucional entiende que corresponderá al Estado, al establecer las bases de aquellos, fijar y justificar la necesidad de realizar una centralización de la gestión por concurrir las circunstancias mencionadas por el precepto.

La doctrina ha visto en esta sentencia un apoyo a una recentralización de competencias en materia de políticas activas de empleo que llevan a preguntarse si no existe el riesgo de un vaciamiento de las competencias ejecutivas de las Comunidades Autónomas y qué margen de actuación les queda para elaborar políticas activas que atiendan a su realidad territorial. Se ha expresado la opinión que en esta Sentencia 22/2014, el Tribunal Constitucional ha ido restringiendo el ámbito competencial autonómico, dejando muy poco espacio para su actuación propia ${ }^{29}$.

Esta decisión de rechazar la vulneración de competencias autonómicas en materia de gestión por el mencionado precepto, así como su argumentación, que pospone a un momento futuro el juicio sobre si dichas competencias son vulneradas o no, son motivo de un severo voto particular que muestra su radical disconformidad con la misma y se basa para ello en una elaborada argumentación, como veremos más adelante.

En cuanto al apartado 2 de la letra $e$ ) del mismo art. 13, su impugnación es también desestimada por entender el Tribunal que se trata del ejercicio de competencias exclusivas del Estado a través de determinados programas de ámbito supraautonómico y que esta doble finalidad justifica la gestión centralizada de dichos programas.

El segundo precepto impugnado al que nos vamos a referir es la disposición adicional cuarta de la Ley 56/2003, según la cual: «Los programas financiados con cargo a la reserva de crédito establecida en su presupuesto de gastos, cuya ejecución afecta a un ámbito geográfico superior al de una Comunidad Autónoma sin que implique la movilidad geográfica de los desempleados o trabajadores participantes en los mismos, podrán ser gestionados por el Servicio Público de Empleo Estatal cuando precisen una coordinación unificada y previo acuerdo entre el Servicio Público de Empleo Estatal y las Comunidades Autónomas en las que vayan a ejecutarse los citados programas» (precepto actualmente recogido en el núm. 2 del apartado b) del art. 18 del Real Decreto Legislativo 3/2015).

Nuevamente la sentencia rechaza la impugnación realizada, pues entiende que la gestión centralizada de la que habla dicho precepto se establece

29 Vid. E. Rojo TorRecilLA, «A vueltas con el reparto competencial en materia laboral», 14 de octubre de 2014, disponible en bttp://www.eduardorojotorrecilla.es/2014/10/a-vueltas-con-el-reparto-competencial.btml. 
como una mera posibilidad, por lo que la eventual vulneración solo se produciría si las disposiciones que desarrollen dichos programas no cumplieran con los requisitos de la doctrina del Tribunal Constitucional. Además, la norma hace preciso un acuerdo previo con las Comunidades Autónomas, por lo que entiende que no se invaden sus ámbitos de competencia.

Como hemos dicho ya, esta sentencia fue objeto de un severo voto particular que expresó su radical discrepancia respecto de la misma con una serie de sólidos argumentos ${ }^{30}$. En concreto, respecto de su fundamento jurídico 7.a) que examina la atribución de competencia al Servicio Público de Empleo Estatal para «gestionar los programas financiados con cargo a la reserva de crédito establecida en su presupuesto de gastos cuya ejecución afecte a un ámbito geográfico superior al de una Comunidad Autónoma, cuando estos exijan la movilidad geográfica de los desempleados o trabajadores participantes en los mismos a otra Comunidad Autónoma distinta a la suya y precisen de una coordinación unificada».

Estos son los rotundos argumentos en los que basa su opinión contraria a la de la mayoría del Tribunal:

- El magistrado discrepante entiende, en primer lugar, que la impugnación llevada a cabo por el Parlamento de Cataluña no puede considerarse como preventiva, ya que cuestiona una construcción legal que supone reservar una competencia ejecutiva al Estado en los términos y casos que el precepto recoge. La falta de carácter preventivo o hipotético de la impugnación planteada se advierte en el tenor literal del precepto, que atribuye facultades de gestión a un órgano estatal. El magistrado que formula dicho voto particular valora como ciertamente «innovador que la pretensión de configurar con carácter general un supuesto de gestión centralizada de ayudas en ámbitos como el laboral, en el que la gestión es, por regla general, autonómica, no suponga una vulneración de las competencias de las Comunidades Autónomas».

- Afirma que el modo de razonar del Tribunal invierte los términos del análisis para no tener que examinar el problema constitucional planteado y «considera que ya se determinará en el futuro si la gestión centralizada está justificada, obviando que lo que hace el precepto es exactamente

${ }^{30}$ Este voto particular está formulado por el magistrado Luis Ignacio Ortega Álvarez, aunque en un voto particular formulado a otra sentencia posterior la magistrada Adela Asua Batarrita dice reconsiderar la postura que mantuvo en dicha sentencia de no adherirse a este voto particular y apela a los argumentos contenidos en este (voto particular formulado contra la STC 179/2016, de 20 de octubre). 
eso, construir con vocación de generalidad un supuesto de gestión centralizada de ayudas. En otros términos, lo que para el legislador estatal ya está justificado, la gestión centralizada en los términos del precepto, la sentencia entiende que ha de determinarse caso a caso cuando sea aplicado [...] dicho legislador ya ha considerado que en los casos a los que se refiere el precepto se dan las condiciones exigidas por la doctrina constitucional para la gestión centralizada de ayudas».

- Defiende que «frente a dicha forma de razonar, en coherencia con el carácter abstracto que es propio del juicio de constitucionalidad, lo que habría debido juzgarse era la pretensión del Estado de configurar, con alcance general, una reserva de gestión de subvenciones en los casos en los que se den los requisitos que el propio precepto establece» y «lo que hubiera debido hacerse es comprobar si los requisitos o condiciones que la norma establece justifican la gestión centralizada por un órgano estatal en los términos de nuestra consolidada doctrina».

- Concluye así que la norma impugnada vulnera el orden constitucional de atribución de competencias de ejecución en materia laboral, puesto que establece la gestión centralizada de subvenciones en una materia en la que la Comunidad Autónoma tiene competencias ejecutivas, y añade que las razones que el precepto establece para justificar la centralización no pueden ser aceptadas como justificativas de tal pretensión centralizadora. Así, el que la ejecución afecte a un ámbito geográfico superior al de una Comunidad Autónoma y que se exija movilidad geográfica a las personas participantes se conectan con la utilización de la supraterritorialidad como criterio atributivo de competencias al Estado, lo cual ha sido reiteradamente rechazado por la doctrina del Tribunal. Además entiende que al examinar el requisito de la necesidad de coordinación unificada el Tribunal incurre en un error conceptual, ya que identifica coordinación unificada con gestión. Ello hace que el precepto se vuelva tautológico, ya que la sentencia entiende que «se gestionará centralizadamente aquello para lo que sea preciso una gestión centralizada». No solo eso, sino, lo que es más grave, se olvida que, conforme a la doctrina constitucional, coordinación no implica la asunción de competencias ejecutivas, sino todo lo contrario: ejercitar un poder de dirección sobre actividades realizadas por otros y no por el mismo ente que va a coordinar; de tal forma que la sentencia desfigura el concepto constitucional de coordinación.

Se trata, por tanto, de un pronunciamiento fuerte y sólidamente criticado tanto a través de dicho voto particular formulado a la propia sentencia como por parte de la doctrina. 


\section{La atribución al Servicio Público de Empleo Estatal de competencias para gestionar los programas financiados con cargo a la reserva de crédito establecida en su presupuesto de gastos en posteriores sentencias del Tribunal Constitucional}

Tras esta primera STC 22/2014 se suceden otras que responden a nuevas impugnaciones referidas, entre otras cuestiones, a esta atribución al SEPE de competencias para gestionar los programas financiados a cargo de la reserva de crédito establecida en su presupuesto de gastos. A estas sentencias nos referiremos a continuación.

\section{A. STC 179/2016, de 20 de octubre, en relación con diversos preceptos de la Ley 17/2012, de 27 de septiembre, de Presupuestos Generales del Estado para el año 2013}

En esta Sentencia el Tribunal Constitucional da respuesta al recurso de inconstitucionalidad interpuesto por el Gobierno de Cataluña en el que impugnaba, entre otros preceptos, la disposición adicional octogésimo primera de la Ley 17/2012 31 , de 27 de diciembre, de Presupuestos Gene-

31 Según este precepto: «El Servicio Público de Empleo Estatal, de conformidad con lo establecido en el art. 13.h) de la Ley 56/2003, de 16 de diciembre, de Empleo, realizará la gestión de las acciones, medidas y programas financiados con cargo a la reserva de crédito de su presupuesto de gastos, que comprenderá las aplicaciones 19.101.000-X.400, 19.101.000-X.401, 19.101.000-X.402, 19.101.000-X.410, 19.101.000-X.411, 19.101.000-X.412, 19.101.000-X.431 y 19.101.241-A.482, desagregadas a través de varios subconceptos según los diferentes ámbitos funcionales de las políticas activas de empleo.

Para financiar las siguientes actuaciones:

a) Acciones y medidas cuya ejecución afecte a un ámbito geográfico superior al de una Comunidad Autónoma cuando estas exijan la movilidad geográfica de las personas desempleadas o trabajadoras participantes en las mismas a otra Comunidad Autónoma distinta a la suya o a otro país y precisen de una coordinación unificada.

b) Acciones y medidas dirigidas tanto a las personas demandantes de empleo como a las personas ocupadas para la mejora de su ocupación mediante la colaboración del Servicio Público de Empleo Estatal con órganos de la Administración General del Estado o sus organismos autónomos, para la realización de acciones formativas, entre otras, aquellas que tengan como objetivo la generación de empleo de calidad y la mejora de oportunidades de las personas trabajadoras, en particular cuando se desarrollen en el marco de planes, estrategias o programas de ámbito estatal, y ejecución de obras y servicios de interés general y social relativas a competencias exclusivas del Estado.

c) Acciones y medidas de intermediación y políticas activas de empleo cuyo objetivo sea la integración laboral de trabajadores inmigrantes realizadas en sus países de origen, facilitando la ordenación de los flujos migratorios. 
rales del Estado para el año 2013, relativa a la gestión por el SEPE de las acciones, medidas y programas establecidos en la letra $b$ ) del art. 13 de la Ley 56/2003, de Empleo, financiados con cargo a la reserva de crédito de su presupuesto de gastos, por entender que esta norma no respetaba las competencias de la Generalitat de Cataluña en materia de políticas activas de empleo.

Como podía esperarse, el Tribunal Constitucional rechaza también en este caso la petición de la Generalitat de Cataluña tras analizar cada uno de los apartados de la norma mencionada (FJ 2).

Respecto de los apartados $a$ ) y $b$ ), la sentencia entiende que son preceptos análogos a los contenidos en el entonces art. 13.e) de la Ley 56/2003, sobre los que ya se pronunció la ya explicada STC 22/2014 y en ella se dio por bueno el reparto constitucional de competencias que establecía la gestión estatal de las mismas, por lo que considera aplicable la misma doctrina recogida por la misma, según la cual la excepcionalidad que determine la atribución al Estado de facultades de gestión en esta materia debe ser valorada en cada caso concreto, lo que obliga a acudir a las disposiciones que en el futuro reglamenten y desarrollen los concretos programas.

En cuanto al apartado c) (acciones y medidas de intermediación y políticas activas de empleo cuyo objetivo sea la integración laboral de trabajadores inmigrantes realizadas en su país de origen, facilitando la ordenación de los flujos migratorios), la sentencia entiende que se trata de medidas que inciden directamente en la ordenación de la entrada de inmigrantes que pueden incluirse entre las acciones dirigidas a favorecer la colocación de trabajadores en los casos de desplazamientos de estos y, por tanto, materia de competencia exclusiva del Estado en el caso de las migraciones exteriores del art. 149.1.2. ${ }^{a} \mathrm{CE}$. De esta forma concluye que la atribución de la gestión al SEPE no puede ser considerada inconstitucional.

d) Programas que se establezcan con carácter excepcional y duración determinada cuya ejecución afecte a todo el territorio nacional, siendo imprescindible su gestión centralizada a los efectos de garantizar la efectividad de las mismas, así como idénticas posibilidades de obtención y disfrute a todos los potenciales beneficiarios.

Dicha reserva presupuestaria opera como reserva de gestión de políticas activas de empleo en los supuestos anteriormente señalados en favor del Servicio Público de Empleo Estatal, no obstante las competencias asumidas por las Comunidades Autónomas en el ámbito del trabajo, el empleo y la formación.

De acuerdo con lo previsto en el art. 14.3 de la citada Ley 56/2003, de 16 de diciembre, los fondos que integran la reserva de crédito no estarán sujetos a distribución territorial entre las Comunidades Autónomas con competencias de gestión asumidas». 
En lo que se refiere al apartado $d$ ) del mismo precepto (programas de carácter excepcional y duración determinada cuya ejecución afecte a todo el territorio nacional, siendo imprescindible su gestión centralizada a los efectos de garantizar su efectividad e idénticas posibilidades de obtención y disfrute a todos los potenciales beneficiarios), el Tribunal entiende que tampoco en este caso puede decirse que exista la invasión de competencias denunciada, ya que «junto con la afectación a todo el territorio nacional se exige que la concurrencia de circunstancias requeridas por la doctrina constitucional para admitir la gestión centralizada de ayudas públicas por un órgano estatal resulte imprescindible para asegurar la plena efectividad de las medidas y para garantizar las mismas posibilidades de obtención y disfrute por parte de sus potenciales beneficiarios en todo el territorio nacional». Y que la concurrencia de estas circunstancias habrá de valorarse en las normas que regulen los programas a los que se refiere dicho precepto, en las que el Estado habrá de justificar la necesidad de una gestión centralizada. Por lo que nuevamente decide que no existe una vulneración efectiva y actual de la competencia autonómica. De tal forma que la criticada STC 22/2014 deja sentir sus efectos también en pronunciamientos posteriores.

De forma consecuente con lo ya ocurrido en la STC 22/2014, también se formula un voto particular a propósito de este pronunciamiento en cuanto desestima el recurso planteado respecto de la disposición adicional explicada ${ }^{32}$. Este voto particular se refiere al carácter preventivo de la impugnación como fundamento principal de la desestimación decidida por el Tribunal Constitucional y que se apoya en la doctrina de la STC 22/2014 ya mencionada. La magistrada que formula dicho voto se remite a lo expuesto en el voto particular formulado contra dicha Sentencia 22/2014 y rechaza nuevamente que se trate de una impugnación preventiva, ya que, a su entender, el precepto objeto de impugnación establece «con vocación de generalidad y permanencia un supuesto de gestión centralizada de ayudas» que vulnera el orden constitucional de distribución de competencias, puesto que las razones que el precepto establece para justificar la centralización pretendida no pueden ser aceptadas.

Añade, además, dicho voto particular que las resoluciones de convocatoria de las ayudas y subvenciones a los que se fiaba la concreción de los criterios legales y reglamentarios ni siquiera justifican la gestión centrali-

\footnotetext{
32 Voto particular formulado por la magistrada Adela Asua Batarrita.
} 
zada, sino que se limitan a remitirse a los criterios generales recogidos en la norma legal. Se refiere con ello a la STC 178/2015 que estimó un conflicto positivo de competencia promovido por la Xunta de Galicia en relación con la Resolución de 22 de septiembre de 2009, del Servicio Público de Empleo Estatal, por la que se convocaba la concesión de subvenciones para la realización de programas específicos de formación e inserción laboral a favor de los jóvenes desempleados en situación o con riesgo de exclusión social. Nos referiremos a esta sentencia más adelante.

B. STC 194/2016, de 16 de noviembre, en relación con diversos preceptos de la Ley 17/2012, de 27 de diciembre, de Presupuestos Generales del Estado para el año 2013

En cuanto a la segunda de las sentencias de este apartado (STC 194/2016) es el Gobierno vasco quien presenta un recurso de inconstitucionalidad, entre otros, contra el mismo precepto que en la sentencia que se acaba de explicar, relativo a la gestión de las acciones, medidas y programas establecidos en la letra b) del art. 13 de la Ley 56/2003, de Empleo. Entre otros motivos, por considerar el Gobierno vasco, al igual que la Generalitat de Cataluña, que la disposición adicional octogésimo primera de la Ley 17/2012, de 27 de diciembre, de Presupuestos Generales del Estado para el año 2013, vulnera el orden constitucional de atribución de competencias al centralizar en manos del SEPE unas partidas presupuestarias que afectan a la competencia de ejecución en materia de empleo.

En su respuesta, el Tribunal Constitucional desestima la impugnación referida a dicha norma y se remite al pronunciamiento que realizó en su STC 179/2016 (que a su vez se refería a la STC 22/2014), al entender que los motivos de dicha impugnación coinciden sustancialmente en ambos procesos.

Del mismo modo, se formula también en este caso un voto particular por parte de la misma magistrada y con los mismos argumentos recogidos en la STC 179/2016, por lo que nos remitimos a lo dicho sobre dicho voto particular formulado a la STC 179/2016. 
Elisabet Errandonea Ulazia El reparto de competencias entre Estado y Comunidades...

C. STC 43/2017, de 27 de abril, en relación con diversos preceptos de la Ley 2/2012, de 29 de junio, de Presupuestos Generales del Estado para el año 2012, en que se establece la gestión centralizada de programas de empleo

Respecto de la tercera de las sentencias de este apartado (STC 43/2017) es también el Gobierno de la Comunidad Autónoma del País Vasco el que cuestiona la constitucionalidad de algunos de los preceptos de la Ley 2/2012, de 29 de junio, de Presupuestos Generales del Estado para 2012, entre ellos la disposición adicional duodécima de dicha ley. Esta disposición tiene el mismo contenido que la disposición adicional octogésimo primera de la Ley 17/2012, de Presupuestos Generales del Estado para el año 2013, por la que se atribuían al SEPE la gestión centralizada de las acciones, medidas y programas financiados con cargo a la reserva de crédito de su presupuesto, de conformidad con lo establecido por el art. 13.h) de la Ley 56/2003, de 16 de diciembre, de Empleo.

La mencionada disposición fue impugnada por la Generalitat de Cataluña y el Gobierno vasco y declarada conforme al orden constitucional por las SSTC 179/2016 y 194/2016, a las que ya nos hemos referido.

Así, esta STC 43/2017 se remite a lo que el Tribunal Constitucional resolvió en su Sentencia 194/2016, de 16 de noviembre, que desestimaba la impugnación planteada con apoyo en la doctrina establecida en la Sentencia 179/2016.

D. STC 100/2017, de 20 de julio, en relación con diversos preceptos del Real Decreto-ley 1/2013, de 25 de enero, por el que se prorroga el programa de recualificación profesional de las personas que agoten su protección por desempleo

En este caso es el Consejo de Gobierno de la Comunidad Autónoma del País Vasco el que presenta un recurso de inconstitucionalidad contra varios artículos del Real Decreto-ley 1/2013, de 25 de enero, que prorroga el denominado Plan PREPARA. Este programa incluye medidas de política activa de empleo a la vez que una ayuda económica para los participantes en el mismo que cumplan una serie de requisitos a la que denomina «ayuda económica de acompañamiento» ${ }^{33}$.

${ }^{33}$ Es el Real Decreto-ley 1/2011, de 11 de febrero, sobre medidas urgentes para pro- 
La normativa reguladora de dicho programa atribuye a los servicios públicos de empleo de las Comunidades Autónomas la competencia de programación y gestión de las medidas de política activa de empleo, mientras que la concesión y pago de las ayudas económicas de acompañamiento se atribuyen al SEPE. Dicha normativa indicaba que la atribución de la gestión directa al SEPE de dicha ayuda económica de acompañamiento se realizaba de conformidad con el art. 13.e) de la Ley 56/2003, de Empleo. El apartado cuarto de este artículo atribuía al SEPE la gestión de programas financiados con cargo a la reserva de crédito establecida en su presupuesto de gastos, consistentes en «programas que se establezcan con carácter excepcional y duración determinada, cuya ejecución afecte a todo el territorio nacional, siendo imprescindible su gestión centralizada a los efectos de garantizar la efectividad de los mismos, así como idénticas posibilidades de obtención y disfrute a todos los potenciales beneficiarios».

El Gobierno vasco impugna, entre otras normas, dicha atribución de competencias al SEPE y alega que, salvo una remisión genérica al art. 13.e).4 de la Ley 56/2003, de Empleo, la normativa reguladora del Plan PREPARA no contiene una justificación formal expresa por la que el Estado asuma la gestión de dicha ayuda económica de acompañamiento que califica como subvención.

Así, el Tribunal Constitucional procede a examinar si en este caso concurren las circunstancias extraordinarias que permitirían recurrir de forma excepcional a la gestión centralizada de dicha ayuda económica por parte del SEPE.

Advierte, en primer lugar, que al tratarse de un programa denominado como de «carácter nacional» no resulta un elemento determinante. En segundo lugar afirma que el hecho de que el legislador encuadre formalmente el Plan PREPARA dentro de los programas descritos en el art. 13.h).4 de la Ley 56/2003 no significa que el diseño normativo de dicho plan responda efectivamente a las características indicadas por el mismo ni que su regulación reúna materialmente las características necesa-

mover la transición al empleo estable y a la recualificación profesional de las personas desempleadas, el que por primera vez reguló dicho plan. Según su art. 2.7: «El Servicio Público de Empleo Estatal será el encargado de la concesión y pago de las ayudas económicas de acompañamiento, en aplicación de lo dispuesto en el art. 13.e).4. ${ }^{\circ}$ de la Ley 56/2003, de 16 de diciembre, de Empleo, las cuales se tramitarán en régimen de concesión directa según lo establecido en el art. 22.2.b) de la Ley 38/2003, de 17 de noviembre, General de Subvenciones». 
rias para apreciar que concurren las circunstancias que justifican la gestión centralizada (FJ 6). Y, en tercer lugar, tampoco considera que de la restante regulación de la ayuda económica pueda deducirse sin esfuerzo la justificación de la acción centralizada.

Entiende que el legislador estatal ha ejercido en esta materia sus competencias para diseñar un régimen de otorgamiento de la ayuda económica que determina una actividad ejecutiva reglada en alto grado, donde las funciones de reconocimiento, concesión y pago requieren constatar y cumplir las condiciones y términos fijados por la normativa del Estado, de tal modo que dichas actuaciones se limitan, en gran medida, a aplicar los requisitos previamente establecidos por la legislación estatal. Además, en este caso, la competencia de programar y gestionar las medidas de políticas activas de empleo del programa se atribuyen a los servicios públicos de empleo autonómicos y el mantenimiento de la ayuda económica está condicionado a que las personas beneficiarias participen en dichas acciones. Así concluye la mayoría del Tribunal que no se puede apreciar que la asunción por parte del SEPE de las funciones de concesión y pago de la ayuda económica resulte imprescindible para garantizar la efectividad y homogeneidad en su disfrute.

En cuanto a la eventual movilidad de las personas beneficiarias de la ayuda económica de acompañamiento, tampoco se aprecia que concurran circunstancias excepcionales que hagan necesario desplazar la gestión centralizada al SEPE. Considera que la competencia legislativa básica que el art. 149.1.13. ${ }^{a} \mathrm{CE}$ atribuye al Estado le permitiría fijar los puntos de conexión oportunos para determinar la Comunidad Autónoma a la que en cada caso correspondería ejercer la concesión y pago de dicha ayuda y podría también establecer técnicas de coordinación mediante las que favorecer el control relativo al cumplimiento de los requisitos exigidos para tener derecho al reconocimiento y mantenimiento de la ayuda económica. Ello haría innecesario la atribución a un único titular de la función de concesión y pago de la ayuda (FJ 6).

Así, la mayoría del Tribunal Constitucional termina concluyendo que en este caso no concurren las circunstancias que, conforme a su doctrina, podrían justificar la atribución al SEPE de las funciones de concesión y pago de la ayuda económica de acompañamiento del programa PREPARA.

Esta sentencia es también objeto de un voto particular que es suscrito por dos magistrados. En este voto particular muestran su discrepancia respecto del título competencial del art. 149.1.13. ${ }^{a}$ CE que la mayoría del Tribunal considera corresponde al Plan PREPARA. Estos magistrados 
estiman que se trata de un título competencial demasiado vago y remoto respecto del asunto enjuiciado. A su entender, dicho Plan PREPARA tiene una doble dimensión: incluye, por un lado, medidas de reinserción, orientación y formación profesional dentro del título competencial del art. 149.1.7. ${ }^{a} \mathrm{CE}$ y, por otro, incluye también medidas económicas de acompañamiento que se encuentran en el art. 149.1.17. . CE. Así, consideran que la concesión y pago de las ayudas económicas del plan corresponden al Estado, y, por tanto, el recurso tenía que haber sido desestimado.

E. STC 178/2015, de 7 de septiembre, en relación con la Resolución de 22 de diciembre de 2009, del Servicio Público de Empleo Estatal, por la que se convoca la concesión de subvenciones para la realización de programas específicos de formación e inserción laboral a favor de los jóvenes desempleados en situación o con riesgo de exclusión social

En este caso es la Xunta de Galicia la que promueve un conflicto positivo de competencia en relación con la Resolución de 22 de diciembre de 2009, del Servicio Público de Empleo Estatal, por la que se convoca la concesión de subvenciones para la realización de programas específicos de formación e inserción laboral a favor de jóvenes desempleados en situación o con riesgo de exclusión social. La Xunta solicita que se anule la totalidad de dicha Resolución, ya que entiende que vulnera las competencias de la Comunidad Autónoma de Galicia y es a esta a la que corresponde la competencia en dicha materia.

Puesto que el objetivo de dichas ayudas es la formación profesional para mejorar la inserción laboral de ciertos colectivos de personas desempleadas con dificultades, entiende la Xunta de Galicia que se inserta en el ámbito de la formación profesional ocupacional, el cual se encuadra dentro del título competencial del art. 149.1.7. ${ }^{a} \mathrm{CE}$ relativo a la legislación laboral. El Tribunal Constitucional comparte dicho criterio de acuerdo con su doctrina ya expresada en sentencias anteriores (STC 195/1996 y otras). Por tanto, en esta materia corresponde al Estado de forma exclusiva dicha legislación laboral, sin perjuicio de su aplicación por los órganos de las Comunidades Autónomas ${ }^{34}$.

${ }^{34}$ Junto al mencionado art. 149.1.7. ${ }^{a}$ CE, el art. 29.1 del Estatuto de Autonomía de Galicia atribuye a la Comunidad Autónoma gallega «la ejecución de la legislación del Estado en materia laboral, asumiendo las facultades, competencias y servicios que en este ámbito y a nivel de ejecución ostenta actualmente el Estado respecto a las relaciones laborales, sin perjuicio de la alta inspección de este. Quedan reservadas al Estado todas las competencias en 
Considera la sentencia que la convocatoria de unas ayudas concretas por un periodo determinado constituye un indiscutible acto de gestión o ejecución, y procede a abordar el examen del aspecto que de manera principal se plantea en relación con dicha disposición, que consiste, en síntesis, en si concurren o no circunstancias específicas que justifiquen la gestión centralizada por parte del SEPE (FJ 5).

Los programas subvencionados por la Resolución de 26 de septiembre de 2009 se dirigían a la formación e inserción laboral a favor de jóvenes desempleados en situación o con riesgo de exclusión social, contemplados en el art. 22.1.b) ${ }^{35}$ y el párrafo tercero del art. $6.4^{36}$ del Real Decreto $395 / 2007^{37}$. Dicho art. 6.4 fue también objeto de impugnación por considerar que invadía competencias ejecutivas autonómicas y fue declarado acorde a la Constitución con los mismos argumentos utilizados por la STC 22/2014 [FJ 2.a)]. Así, considera que serán las disposiciones que en el futuro reglamenten las acciones formativas las que permitirán apreciar si concurren o no las circunstancias que justifiquen la excepcionalidad que determine la atribución al Estado de facultades de gestión (FJ 6).

De acuerdo con el apartado 2 del art. 1. ${ }^{\circ}$ de la Resolución de 22 de septiembre de 2009, la gestión centralizada de los programas que se subvencionan a través de la misma está justificada, ya que «la ejecución de los proyectos de formación afectará a un ámbito territorial superior al de una Comunidad Autónoma y facilitará la movilidad de los participantes en los mismos requiriendo, por tanto, la coordinación unificada del Servicio

materia de migraciones interiores y exteriores, fondos de ámbito nacional y de empleo, sin perjuicio de lo que establezcan las normas del Estado sobre esta materia».

35 Esto es: «Los programas específicos que establezca el Servicio Público de Empleo Estatal para la formación de personas con necesidades formativas especiales o que tengan dificultades para su inserción o recualificación profesional. En la ejecución de estos programas podrán participar instituciones públicas o entidades sin ánimo de lucro que tengan entre sus fines la formación o inserción profesional de los colectivos de trabajadores a los que se dirigen estos programas».

${ }^{36}$ De acuerdo con este: «Asimismo, se entiende que requieren de una acción coordinada y homogénea las acciones formativas que incluyan compromisos de contratación de desempleados cuando su ejecución afecte a centros de trabajo ubicados en el territorio de más de una Comunidad Autónoma, así como las dirigidas a colectivos con necesidades formativas especiales o que tengan dificultades para su inserción o recualificación profesional cuando su ejecución, afectando a un ámbito geográfico superior al de una Comunidad Autónoma y precisando una coordinación unificada, exija la movilidad geográfica de los participantes».

37 Real Decreto 395/2007, de 23 de marzo, por el que se regula el subsistema de formación profesional para el empleo. Esta norma fue derogada por el Real Decreto 694/2017, de 3 de julio, por el que se desarrolla la Ley 30/2015, de 9 de septiembre, por la que se regula el Sistema de Formación Profesional para el Empleo en el ámbito laboral. 
Público de Empleo Estatal, según lo establecido en el art. 13, apartado $e$ ), de la Ley 56/2003, de Empleo».

Sin embargo, la sentencia estima que dichas previsiones no están especificadas posteriormente en la resolución al identificar y definir las acciones subvencionables ni los criterios de valoración, sino tan solo cuando se señala que pueden solicitar las subvenciones las asociaciones o fundaciones «cuya actuación sea de ámbito nacional» (FJ 7). Por ello, dice, «con estas previsiones no podemos sino afirmar que no queda justificada la gestión centralizada de las subvenciones, pues la resolución ha construido un supuesto de gestión centralizado por parte del Servicio Público de Empleo Estatal que aparentemente se ajustaría al conjunto de los criterios del art. 6.4 del Real Decreto 395/2009, pero que, en realidad, no hace otra cosa que ir añadiendo una serie de notas que no coinciden estrictamente con las del citado precepto y que [...] no permitirían en ningún caso atribuir la gestión de las subvenciones a un órgano estatal, privando de la misma a las Comunidades Autónomas que tienen atribuidas las competencias de ejecución en virtud de sus respectivos Estatutos de Autonomía» (FJ 7).

En cuanto al requisito de «coordinación unificada del Servicio Público de Empleo Estatal, según lo establecido en el art. 13, apartado $e$ ), de la Ley 56/2003, de Empleo, la sentencia considera que carece de eficacia justificativa para reservar la gestión de las subvenciones al Servicio Público de Empleo Estatal. Entre otros motivos, afirma que la necesidad de coordinación estatal no se solventa reservando al Estado la competencia ejecutiva (supuesto que se produce, por el contrario, cuando la coordinación no permite solucionar la cuestión), sino a través de la competencia de coordinación general que ostentan, como complemento inherente a su competencia en la materia, para garantizar que no haya disfunciones y que presupone la existencia de competencias de las Comunidades Autónomas que deben ser coordinadas y que el Estado debe respetar al desarrollar su función de coordinación» (FJ 9).

Termina dicho fundamento jurídico afirmando: «En el presente supuesto no se advierte en la resolución impugnada la existencia de ninguna circunstancia que suponga un obstáculo para que el Estado pueda llevar a cabo en debida forma su potestad de coordinación para solventar las posibles disfunciones que se pudieran producir en la gestión de las subvenciones, máxime cuando el propio Estado, en ejercicio de sus competencias normativas plenas, puede fijar, con el grado de detalle que considere necesario, todas las condiciones relativas a las subvenciones de que se 
trata, incluidos los puntos de conexión precisos, por lo que no está justificado desposeer a las Comunidades Autónomas de la gestión al socaire de esta necesidad de coordinación unificada».

\section{A MODO DE CONCLUSIÓN}

El art. 13.e) de la Ley 56/2003, de 16 de diciembre, de Empleo (en la actualidad, art. 18, apartado h), del Real Decreto Legislativo 3/2015, de 23 de octubre), ha resultado ser un artículo ciertamente polémico por las competencias de gestión atribuidas al Estado en materia de empleo. Dicho artículo fue objeto de impugnación tras su publicación. La sentencia del Tribunal Constitucional que dio respuesta a dicha impugnación tras diez años de espera resultó insatisfactoria y fue objeto de un severísimo voto particular. Este voto particular entendía que el Tribunal Constitucional eludía examinar el problema constitucional planteado ante un precepto que construía con vocación de generalidad un supuesto de gestión centralizada de ayudas por parte del SEPE, a pesar de que la competencia de ejecución de la legislación laboral corresponde a las Comunidades Autónomas. Y ello sin comprobar si los requisitos que establecía dicha norma justificaban la gestión centralizada por un órgano estatal de acuerdo con la doctrina del propio Tribunal Constitucional.

Por su parte, varias Comunidades Autónomas han presentado sucesivos recursos contra disposiciones aprobadas al amparo del mencionado artículo y en varias de ellas han obtenido una respuesta favorable a sus pretensiones al considerar el Tribunal Constitucional que los concretos programas impugnados vulneraban el orden constitucional de competencias al reconocerse al SEPE competencias de gestión de forma injustificada conforme a su doctrina.

De esta forma dicho reconocimiento de competencias de ejecución en materia laboral al SEPE ha resultado ser una puerta abierta a la vulneración de competencias autonómicas en la materia y un precepto ante el cual las Comunidades Autónomas han de permanecer alerta de cara a defender las competencias que constitucionalmente les han sido atribuidas. 